\title{
Developing Continuous SCM/CRM Forcing Using NWP Products Constrained by ARM Observations
}

S. Xie, R.T. Cederwall, J.J. Yio, M. Zhang

April 29, 2002

U.S. Department of Energy

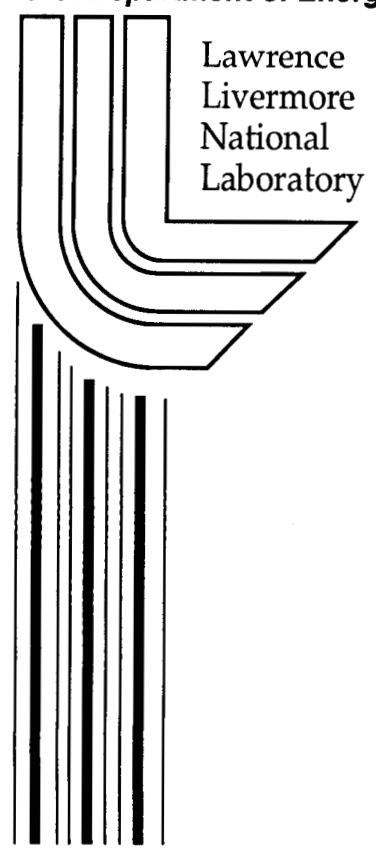




\section{DISCLAIMER}

This document was prepared as an account of work sponsored by an agency of the United States Government. Neither the United States Government nor the University of California nor any of their employees, makes any warranty, express or implied, or assumes any legal liability or responsibility for the accuracy, completeness, or usefulness of any information, apparatus, product, or process disclosed, or represents that its use would not infringe privately owned rights. Reference herein to any specific commercial product, process, or service by trade name, trademark, manufacturer, or otherwise, does not necessarily constitute or imply its endorsement, recommendation, or favoring by the United States Government or the University of California. The views and opinions of authors expressed herein do not necessarily state or reflect those of the United States Government or the University of California, and shall not be used for advertising or product endorsement purposes.

This work was performed under the auspices of the U. S. Department of Energy by the University of California, Lawrence Livermore National Laboratory under Contract No. W-7405-Eng-48.

This report has been reproduced directly from the best available copy.

Available electronically at http://www.doe.gov/bridge

Available for a processing fee to U.S. Department of Energy

and its contractors in paper from

U.S. Department of Energy

Office of Scientific and Technical Information

P.O. Box 62

Oak Ridge, TN 37831-0062

Telephone: (865) 576-8401

Facsimile: (865) 576-5728

E-mail: reports@adonis.osti.gov

Available for the sale to the public from

U.S. Department of Commerce

National Technical Information Service

5285 Port Royal Road

Springfield, VA 22161

Telephone: (800) 553-6847

Facsimile: (703) 605-6900

E-mail: orders@ntis.fedworld.gov

Online ordering: http://www.ntis.gov/ordering.htm

OR

Lawrence Livermore National Laboratory

Technical Information Department's Digital Library

http://www.llnl.gov/tid/Library.html 


\title{
Developing Continuous SCM/CRM Forcing Using NWP Products Constrained by ARM Observations
}

\author{
Shaocheng Xie, Richard T. Cederwall, J. John Yio \\ Lawrence Livermore National Laboratory, Livermore, CA, USA \\ Minghua Zhang \\ State University of New York, Stony Brook, NY, USA
}

\section{Introduction}

This study examines the feasibility of using numerical weather prediction (NWP) model products to replace radiosondes to develop long-term continuous forcing, instead of just Intensive Operational Periods (IOPs), for Single Column Models (SCMs) and Cloud Resolving Models (CRMs). This is motivated by the need of long-term continuous forcing for statistical studies of SCMs/CRMs results. Studies have shown that SCMs/CRMs results are sensitive to their detailed initial conditions. One way to reduce this sensitivity is through statistical studies of SCMs/CRMs results so that one can filter out those uninteresting random errors and focus on those physically important systematic errors. The long-term forcing can be obtained directly from NWP model analyses, but the forcing is largely affected by model physical parameterizations that are used in the data analysis procedure. To reduce the problem, we propose a combined NWP data analysis and the ARM objective variational analysis approach to derive the long-term continuous forcing. In the combined system, NWP data provide vertical distribution of atmospheric state variables and the variational analysis is used to derive the required large-scale forcing data constrained by the ARM surface and top of the atmosphere (TOA) measurements. We have conducted a preliminary study using data from the NOAA mesoscale model RUC (Rapid Update Cycle) analysis during the ARM SCM Summer 97 and Spring 2000 IOPs for this study. Results are compared with those from the ARM operational objective variational analysis (Zhang and Lin, 1997; Zhang et al. 2000a,b) and those from the ECMWF (European Center for Medium-range Weather Forecast) analysis. Impacts of the derived forcing on CCM3 SCM are also analyzed.

\section{Problems with the large-scale forcing directly from NWP analysis}

Figures $1 \mathrm{a}, \mathrm{b}$ respectively compare the vertical velocity produced from the ECMWF analysis for the ARM Southern Great Plains (SGP) site with that derived from the ARM variational analysis during summer 97 IOP. For comparison, the observed and model produced surface precipitation rates during the same periods are shown in Fig. 1c. It is seen that the surface precipitation rates are closely coupled with the large-scale vertical motions. Corresponding to these precipitation events, large-scale upward motions are seen in the vertical velocity field. However, the ECMWF model largely underestimates most of the observed precipitation events and it also shows problems in capturing the timing of these convective events. As the result, the model upward motions are much weaker than those derived from the ARM variational analysis. For some periods, such as on day 177 , they are even out of phase. During this day, weak downward motion is seen in the model 
analysis while very strong upward motion is seen in the variational analysis corresponding to the observed strong convective event. As shown later, using the large-scale forcing directly from the ECMWF analysis will cause serious problems in driving SCMs.
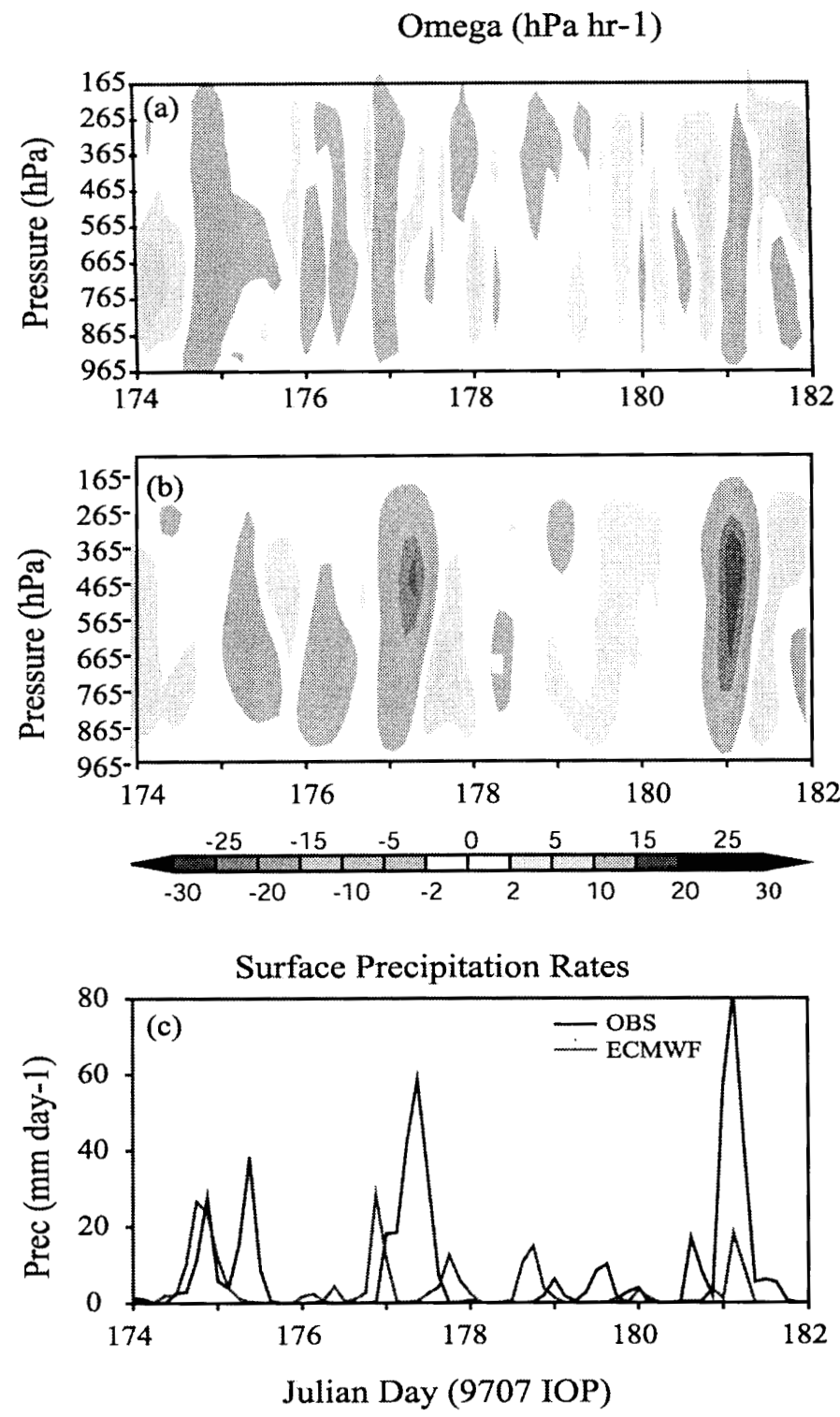

Figure 1. Vertical velocity (hpa $\mathrm{hr}^{-1}$ ) from (a) the ECMWF analysis and (b) the ARM variational analysis, and the model produced (red) and observed (blue) surface precipitation rates (mm day ${ }^{-1}$ ) (c) for the summer 97 IOP. 


\section{New approach and experiments}

This paper proposes a new approach to derive long-term continuous forcing for SCMs/CRMs. As shown in Fig. 2, the new approach uses NWP products to provide vertical profiles of atmospheric state variables (e.g., winds (u, v), temperature $(\mathrm{T})$, and moisture (q)) during the period when radiosondes are not available and uses the ARM objective variational analysis to derive the required large-scale forcing data constrained by the ARM surface and TOA measurements.

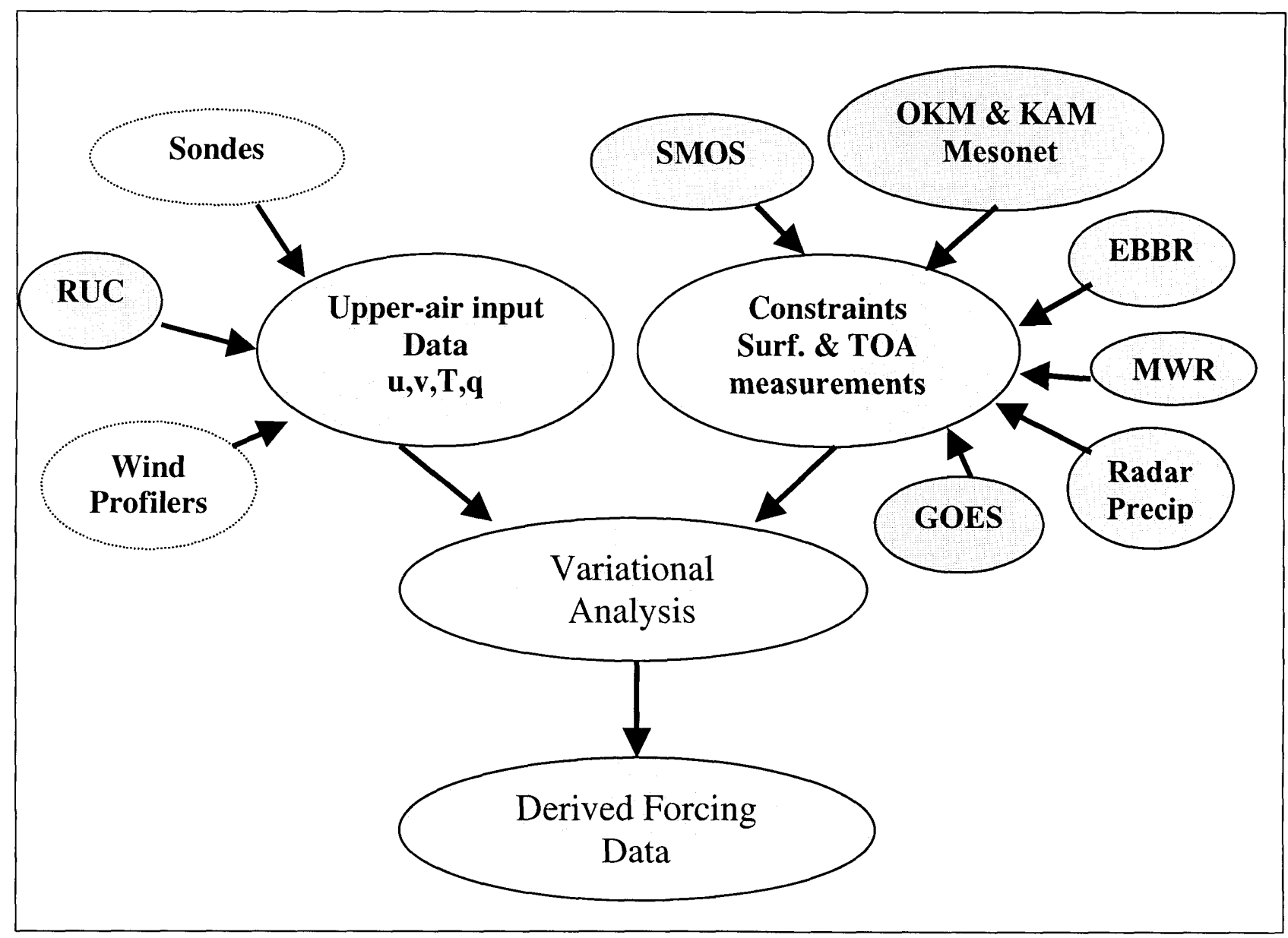

Figure 2. A new approach to derive the long-term continuous forcing using NWP products constrained by the ARM observations.

In this study, we use NOAA mesoscale model RUC analysis to provide the required upper-air input data. The surface and TOA constraints are from (1) the Surface Meteorological Observation Stations (SMOS) that measure surface precipitation, surface pressure, surface winds, temperature and relative humidity; (2) The Oklahoma and Kansas mesonet stations (OKM and KAM) that measure surface precipitation, pressure, winds and temperature; (3) The Energy Budget Bowen Ratio (EBBR) stations that measure surface latent and sensible heat fluxes and surface broadband net radiative flux; (4) The microwave radiometer (MWR) stations that measure the column 
precipitable water and total cloud liquid water; (5) Radar rainfall; and (6) Geostationary Operational Environment Satellite (GOES) that measures clouds and broadband radiative fluxes (Minnis et al., 1995).

Table 1 summarizes the experiments we performed in this study. The control run is the standard approach that is currently used in the ARM operational objective variational analysis. In the study, we test sensitivity of the derived forcing to the use of upper-air input data from RUC analysis, wind profilers (for wind fields only, $\mathrm{T}$ and $\mathrm{q}$ are from RUC analysis), and changes in the length scale used in the Barnes interpolation scheme (Barnes, 1964) in the objective analysis. The largescale forcing derived from ECMWF analysis is used for comparison purpose.

Table 1. Summary of Experiments

\begin{tabular}{|l|l|}
\hline Experiments & Descriptions \\
\hline CONTL & $\begin{array}{l}\text { Control run. }(\mathrm{T}, \mathrm{q}) \text { are from sondes; }(\mathrm{u}, \mathrm{v}) \text { are from sondes merged with wind } \\
\text { profiler data; First guess is from RUC analysis }\end{array}$ \\
\hline RUC & $(\mathrm{u}, \mathrm{v}, \mathrm{T}$, and $\mathrm{q})$ are all from RUC analysis \\
\hline PROF & $(\mathrm{u}, \mathrm{v})$ are from wind profilers and $(\mathrm{T}, \mathrm{q})$ from RUC analysis \\
\hline SCALE & $\begin{array}{l}\text { Same as CONTL except the length scale used in the objective analysis is } \\
\text { changed from (Lx=Ly=50 km, Lt=3hr) to (Lx=Ly=100km, Lt=6hr) } \\
\text { Forcing derived from the ECMWF analysis for the ARM SGP site }\end{array}$ \\
\hline
\end{tabular}

Note: ALL above experiments expect for ECMWF are used the same surface and TOA constraints.

\section{Results analysis}

\section{Upper-air input data}

The root-mean-square (rms) errors for the upper-air input data (u, v, T, and $\mathrm{q}$ ) for experiments RUC, PROF, and ECMWF are shown in Fig. 3 for the summer 97 IOP. The rms errors are calculated using the truth from CONTL against those from RUC, PROF, and ECMWF. For comparison, the standard deviations (black lines) of these upper-air input data in CONTL are also shown in the figure. It is seen that the RUC analysis generally shows rms errors of around $1 \mathrm{~m} \mathrm{~s}^{-2}$ in the wind fields, $0.5 \mathrm{~K}$ in temperature field $(200-900 \mathrm{hPa})$, and less than $1.5 \mathrm{~g} / \mathrm{kg}$ in moisture field. These are comparable to the uncertainties in the observations and are much smaller than the observed temporal variability. It is interesting to see that, in the upper troposphere, RUC shows smaller rms errors in the wind fields in comparison with PROF. Note that the rms errors for temperature and moisture for PROF are not shown in the figure because these two fields are from RUC analysis. The rms errors are larger for ECMWF analysis than RUC and PROF. One of the reasons is that RUC analysis data are used as the first guess in CONTL. 
RMS Errors
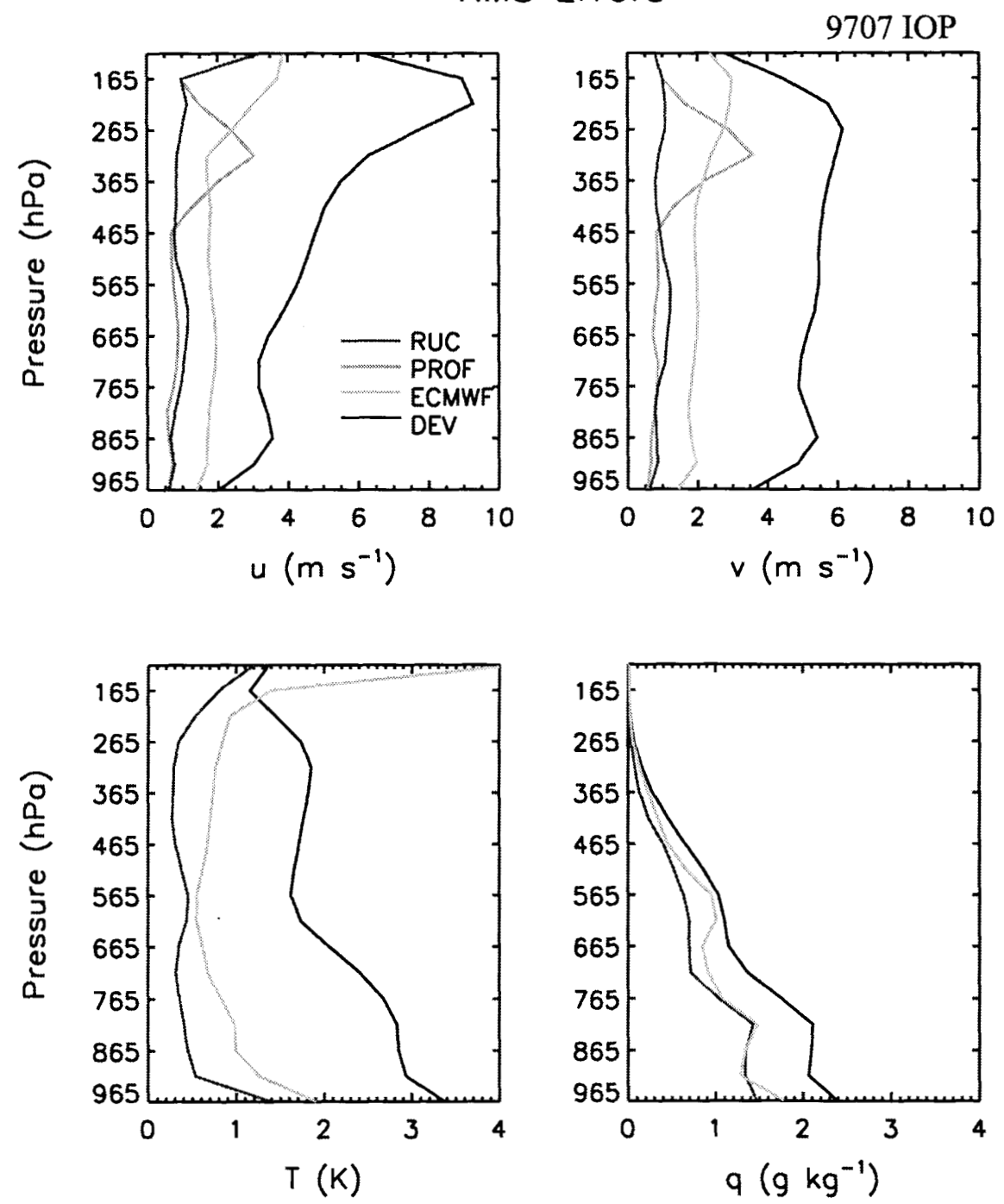

Figure 3. Root-mean-square errors for the upper-air input data (u, v, T, q) for experiments RUC, PROF, and ECWMF, compared to CONTL for the summer 97 IOP. Black lines are the standard deviations of these variables in CONTL.

\section{Derived large-scale forcing}

The rms errors for the derived large-scale forcing fields from these experiments (see Table 1) for the summer 97 IOP and spring 2000 IOP are shown in Figs. 4a, b and Figs. 4c,d, respectively. Here we only show the large-scale advective tendency of temperature and the vertical velocity. One important feature is that, with the constraints, the variational analysis desensitizes the final products to the differences in the input data. For example, although considerable differences exist in RUC and PROF in the wind fields in the upper troposphere, both show very similar rms errors for the derived forcing fields. These rms errors are also comparable to SCALE, which represents one of the uncertainties in the large-scale forcing derived from the current variational analysis (CONTL). It is seen that the rms errors are smaller than the observed variability, especially for the spring 2000 IOP. It is noted that the large-scale forcings from the ECMWF analysis have rather 
large rms errors, especially near the surface for the temperature forcing. The large rms errors in the ECMWF analysis mainly reflect impacts of the model imperfect physical parameterizations on the derived forcing fields.

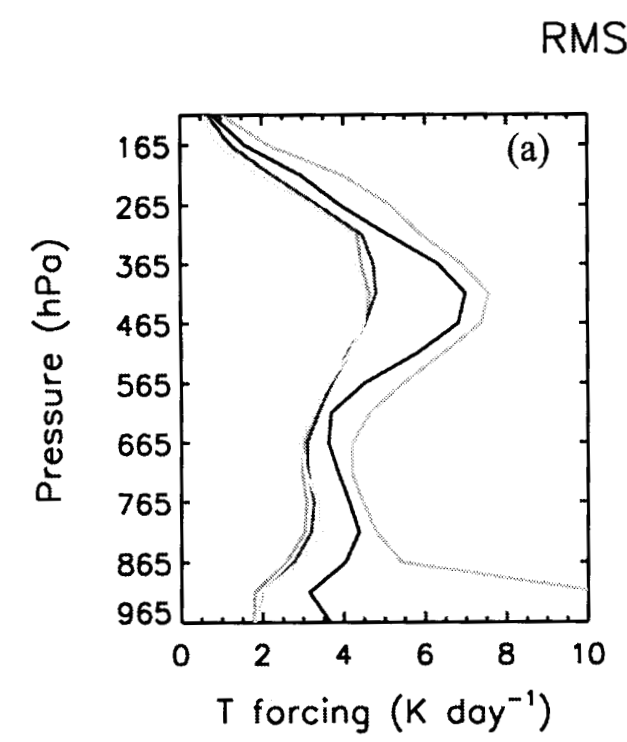

\section{Errors}
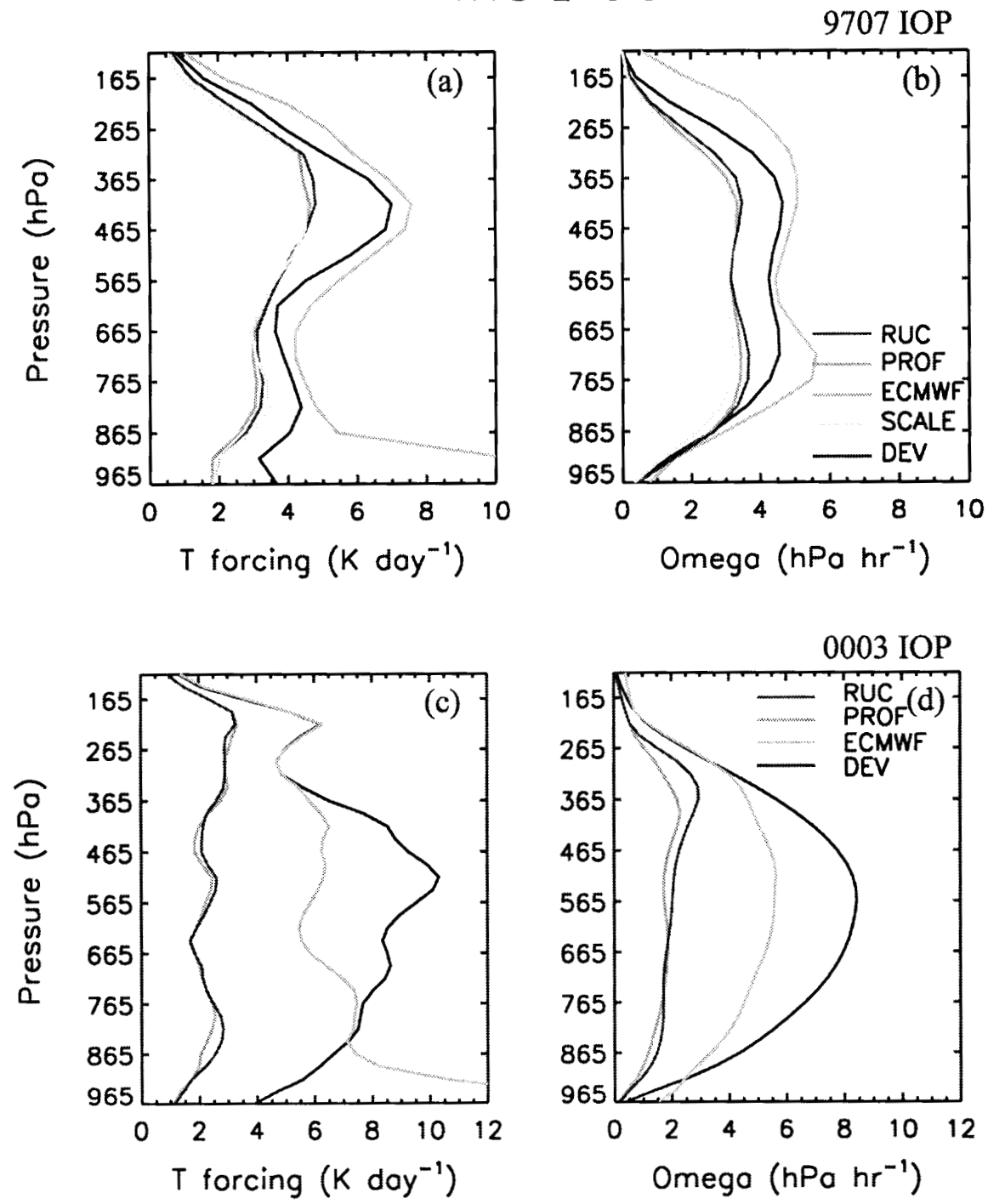

Figure 4. Root-mean-square errors for the derived large-scale advective tendency of temperature $\left(\mathrm{K} \mathrm{day}^{-1}\right)$ and vertical velocity $\left(\mathrm{hPa} \mathrm{hr}{ }^{-1}\right.$ ) from experiments RUC, PROF, SCALE (only for the summer 97 IOP) and ECWMF, compared to CONTL. The upper panels (a,b) are for the summer 97 IOP and the low panels $(\mathrm{c}, \mathrm{d})$ are for the spring 2000.

\section{SCM simulations}

The NCAR CCM3 SCM is used to investigate impacts of the derived large-scale forcing on SCM simulations. The large-scale total advective tendencies of temperature and moisture are specified 
from the derived forcing fields and the surface forcing is calculated by the model surface parameterizations. Figures $5 \mathrm{a}, \mathrm{b}$ respectively show model simulation errors in temperature and moisture fields. It is seen that the SCM does show sensitivity to the large-scale forcing in temperature. Compared to the control run (CONTL), RUC reduces the errors in the upper troposphere, but increases the errors in the middle and lower troposphere. For moisture, they produce similar results as CONTL. For the simulated precipitation (Fig. 5c), RUC and CONTL show very similar results. Results from PROF are very similar to RUC. However, the SCM with the ECMWF analysis forcing fails to reproduce almost all the observed precipitation events.

\section{Simulation Errors}
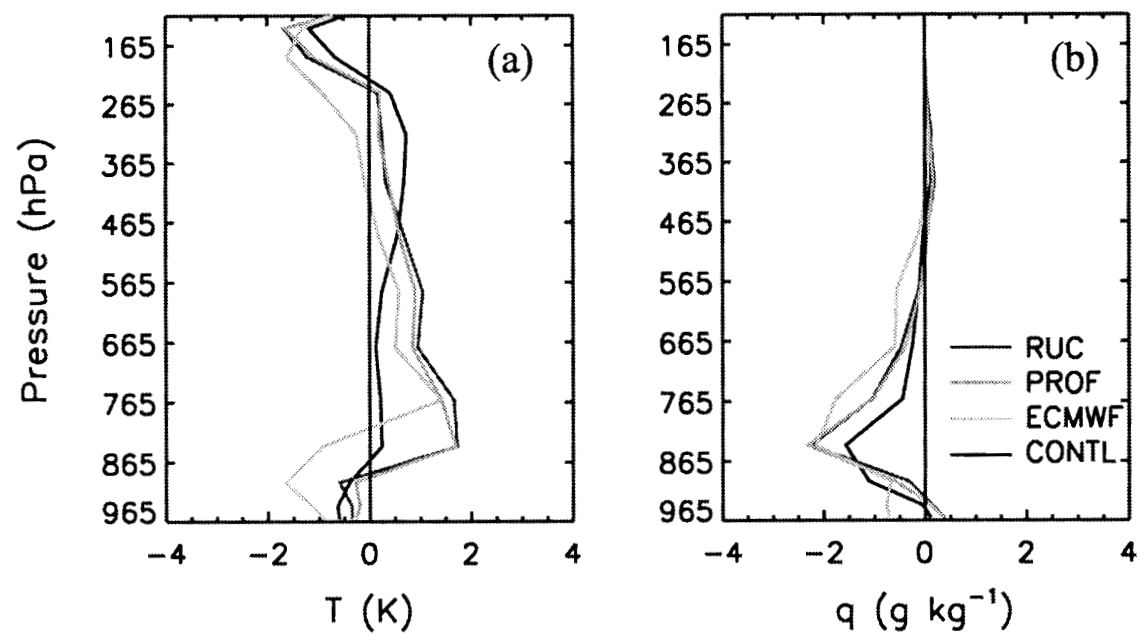

Surface Precipitation

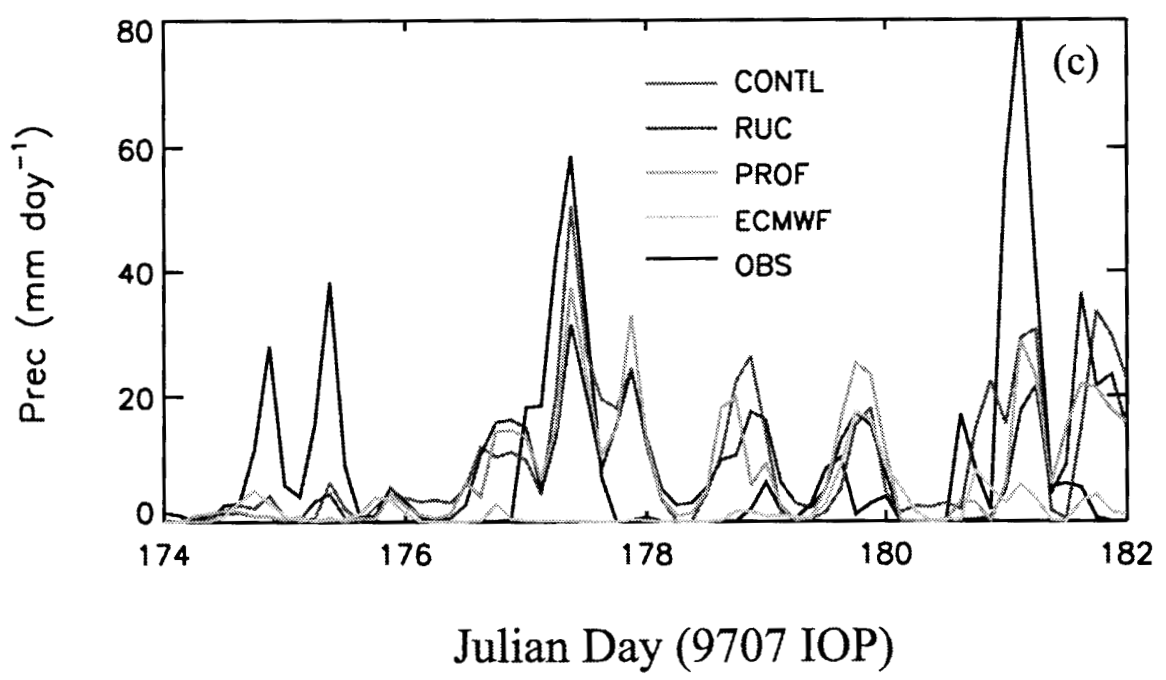

Figure 5. (a) Temperature biases, (b) moisture biases, and (c) surface precipitation rates produced from CCM3 SCM driven by the forcing derived from experiments CONTL, RUC, PROF, and ECWMF during the summer 97 IOP. 


\section{Summary}

1. Compared to the large-scale forcing directly from NWP (ECMWF) analysis, the forcing derived from the new approach is physically consistent with the ARM surface and TOA measurements. Impacts of model physical parameterizations on the derived forcing are considerably reduced. The rms errors in the forcing derived from using RUC analysis are comparable to that with wind profiler data added and changes in some parameters (e.g., length scale) used in the interpolation scheme in CONTL. They are smaller than the range of observed temporal variability.

2. When driving the CCM 3 SCM with the derived forcing from RUC, similar simulation results are obtained in moisture and surface precipitation rates but relatively larger differences are seen in temperature field in comparison with the control run (CONTL).

3. Due to impacts of model imperfect physical parameterizations and inability to capture mesoscale features, the forcing from the ECMWF analysis shows rather large differences compared with those derived from the ARM variational analysis. The CCM3 SCM with the ECMWF forcing fails to capture almost all the observed convective events. This suggests that using forcing directly from NWP analysis needs to be cautiously.

\section{Future plans}

1. Use retrievals to improve vertical structures of temperature and moisture in the boundary layer.

2. Incorporate 4 times/day radiosondes at central facility during non-IOP into the variational analysis system to further improve the results.

3. Derive advective tendencies of cloud liquid and ice water using the combined approach.

Acknowledgments. This research was supported primarily under the U. S. Department of Energy Atmospheric Radiation Measurement (ARM) Program. Work at SUNY Stony Brook was supported by ARM grant DE-FG02-98ER62570, and was also supported by NSF under grant ATM9701950. Work at LLNL was performed under the auspices of the U. S. Department of Energy by the University of California, Lawrence Livermore National Laboratory under contract No. W-7405-Eng-48.

\section{Corresponding Author}

Dr. Shaocheng Xie, xie2@1lnl.gov, 925-422-6023.

\section{References}

Barnes, S. L., 1964: A technique for maximizing details in numerical map analysis. J. Appl. Meteor., 3, 396-409.

Minnis, P., W. L. Smith, D. P. Garber, J. K. Ayers, and D. R. Doeling, 1995: Cloud properties derived from GOES-7 for spring 1994 ARM Intensive Observing Period using version 1.0.0 of 
ARM satellite data analysis program. NASA Ref. Publ. 1366, 59pp. [Available from NASA Langley Research Center, Technical Library, MS 185, Hampton, VA 23655-5225.]

Zhang, M. H., and J. L. Lin, 1997: Constrained variational analysis of sounding data bases on column-integrated budgets of mass, heat, moisture, and momentum: Approach and application to ARM measurements. J. Atmos. Sci., 54, 1503-1524

Zhang, M. H., J. L. Lin, R. T. Cederwall, J. J. Yio, and S. C. Xie, 2001a: Objective analysis of ARM IOP Data: Method and sensitivity. Mon. Weather Rev., 129, 295-311

Zhang, M. H., S. C. Xie, R. T. Cederwall, and J. J. Yio, 2001b: Description of the ARM Operational Objective Analysis System. DOE ARM Technical Report. 16pp. ARM-TR-005. 